\title{
Royal Naurūz in Samarkand. Pisa-Roma, 2006, 227 p. (Rivista degli Studi Orientali, Nuova Serie, vol. LXXVIII, Supplemento ${ }^{\circ} 1$ )
}

\section{Frantz Grenet}

\section{(2) OpenEdition}

1 Journals

\section{Édition électronique}

URL : http://journals.openedition.org/abstractairanica/37530

DOI : 10.4000/abstractairanica.37530

ISSN : 1961-960X

Éditeur :

CNRS (UMR 7528 Mondes iraniens et indiens), Éditions de l'IFRI

\section{Édition imprimée}

Date de publication : 8 avril 2010

ISSN : 0240-8910

\section{Référence électronique}

Frantz Grenet, «Royal Naurūz in Samarkand. Pisa-Roma, 2006, 227 p. (Rivista degli Studi Orientali, Nuova Serie, vol. LXXVIII, Supplemento n 1) », Abstracta Iranica [En ligne], Volume 30 | 2010, document 6, mis en ligne le 08 avril 2010, consulté le 27 septembre 2020. URL : http://journals.openedition.org/ abstractairanica/37530 ; DOI : https://doi.org/10.4000/abstractairanica.37530

Ce document a été généré automatiquement le 27 septembre 2020.

Tous droits réservés 


\title{
Royal Naurūz in Samarkand. Pisa- Roma, 2006, 227 p. (Rivista degli Studi Orientali, Nuova Serie, vol. LXXVIII, Supplemento $\mathrm{n}^{\circ} 1$ )
}

\author{
Frantz Grenet
}

1 Ce volume constitue les Actes d'une journée d'études qui s'était tenue l'année précédente au Centre d'Études Arméniennes de Venise et était entièrement consacrée à l'étude d'un seul et même programme iconographique, à savoir la salle peinte dite " des Ambassadeurs ", découverte accidentellement en 1965 sur le site d'Afrasiab, premier emplacement de la ville de Samarkand.

2 Ce cycle pictural datable des environs de 660, une cinquantaine d'années avant la conquête arabe à Samarkand, méritait assurément qu'on lui consacrât aujourd'hui un ouvrage spécifique, d'abord en raison de son caractère et de sa qualité uniques parmi tout ce qui est connu de la peinture de l'Asie centrale, ensuite en raison des progrès intervenus dans son interprétation depuis les premières publications en russe. Répartie sur les quatre murs d'une grande salle de réception, la composition correspond visiblement à une commande qui, même privée (ce qui est une possibilité), reflète la propagande du roi Varkhumān, nommé dans une inscription sogdienne intégrée dans la peinture. Le personnage est attesté par les monnaies et par les annales chinoises comme roi de Samarkand et allié des Tang dans les années 650. Le mur principal (à l'ouest) figure des cortèges d'ambassadeurs portant des cadeaux et qui se déploient au milieu de gardes et d'officiers turcs. Les ambassades viennent de principautés voisines, mais aussi du Tibet et surtout de Chine tandis que deux Coréens, sans cadeaux, pourraient être des gardes exotiques intégrés à la délégation chinoise. Le mur sud représente le cortège du roi de Samarkand apportant des animaux offerts en sacrifice au mausolée de ses parents, selon une coutume sogdienne du Nouvel An dont témoignent des textes chinois. Le mur nord est consacré à des scènes de la vie à la cour chinoise. Le mur est, mal conservé, semble évoquer l'Inde. Les échanges préparatoires à 
la table ronde ici publiée avaient permis des avancées substantielles, notamment la reconnaissance d'un synchronisme calendaire qui sous-tend l'ensemble du programme : en 660 le solstice d'été, le sixième jour du Nouvel an sogdien consacré aux célébrations royales ainsi que la fête chinoise dite des «bateaux dragons » (Duanwujie) figurée au mur nord, avaient tous lieu le même jour, et à un petit décalage près c'était le cas aussi en 663. On comprend mieux, dès lors, que les thèmes de la royauté solaire et des nations communiant dans la fête soient patents ou détectables sur plusieurs des panneaux.

3 Il s'en faut de beaucoup, cependant, que l'accord soit général sur tous les détails, et comme Étienne de la Vaissière le souligne dans la Préface il a paru souhaitable de présenter au lecteur les divergences qui subsistent. Voici une brève présentation de chaque article (les contributions sont précédées par un dossier commun, réunissant des photographies en couleur et les relevés de toutes les parties conservées) :

4 - E. Kageyama, "Coiffure et vêtement des Chinoises sur la peinture d'Afrasiab" (la mode ici figurée trouve des parallèles très proches avec les peintures de la tombe de la princesse Xincheng, morte en 663 et sœur de l'empereur Gaozong qui est figuré sur le même mur nord);

5 - F. Grenet, « What was the Afrasiab painting about? (défend l'idée selon laquelle c'est la figure du roi Varkhumān qu'il convient de restituer en haut de la scène de remise des cadeaux figurée au mur ouest, lequel offrirait une présentation combinée des trois premiers jours du Nowruz; par ailleurs l'assimilation du souverain à Yima, roi solaire et roi de la concorde universelle, sous-tendrait l'ensemble du programme iconographique);

6 - V. Livšic, "The Sogdian wall inscriptions on the site of Afrasiab" (améliore et complète ses lectures antérieures publiées dans le livre de L. I. Al'baum, Živopis' Afrasiaba, Taškent, 1975);

7 - B. I. Marshak, "Remarks on the murals of the Ambassadors Wall» (propose de restituer à la partie supérieure du mur ouest l'image des dieux de Samarkand, en conformité avec les règles observées à Pendjikent pour le mur principal des salles de réception);

8 - F. Ory, "Essai de restitution des parties manquantes de la peinture d'Afrasiab" (justifie chaque choix de restitution par des parallèles dans l'art sogdien; ses restitutions sont utilisées ici dans l'article de F. Grenet, et ultérieurement dans ceux qu'a publiés ailleurs M. Compareti);

9 - M. Mode, "Reading the Afrasiab murals: some comments on reconstructions and details» (critique avec pertinence certains détails des restitutions susmentionnées; suppose que le mur ouest était dominé par les deux figures de Varkhumān et du qaghan des Turcs, ce qui ferait la synthèse des propositions de Grenet et de de La Vaissière ; identifie l'un des délégués comme Yazdgird III, ce qui l'amène à dater l'ensemble c. 650, plus tôt que les dates admises par la plupart des autres contributeurs au volume);

10 - V.I. Raspopova, «Ethnos and weaponry in the murals of Afrasiab» (certains équipements alors communs à plusieurs peuples d'Asie centrale ont été arbitrairement distribués entre les divers groupes ethniques - Sogdiens, Bactriens, Turcs, Chinois -, pour servir de marqueurs identitaires);

11 - É. de La Vaissière, "Les Turcs, rois du monde à Samarcande» (la présence de nombreux Turcs de statuts divers sur le mur ouest, ainsi que la répartition des murs 
entre divers peuples - or les Sogdiens occupent déjà le mur sud - ne pourrait s'expliquer que si c'est un qaghan qui préside; en 660 il y a deux qaghans, Buzhen et Mishe, soumis aux Chinois mais restant les maîtres théoriques de la Sogdiane ; dans des articles antérieurs l'A. avait proposé d'autres candidats, d'époques antérieures);

12 - S. Cristoforetti, "Afrāsyāb toponimo e Afrāsyāb eponimo: considerazioni sulla riemergente plausabilità di una lectio facilior » (hypothèses sur les mythes iraniens qui ont pu se cristalliser autour du toponyme, notamment les mythes liés aux eaux);

13 - M. Compareti, "A reading of the royal hunt at Afrāsyāb based on Chinese sources » (le mur nord évoquant la Chine est inspiré de plusieurs rouleaux peints importés de ce pays, évoquant deux fêtes distinctes, celle des «bateaux dragons » reproduite dans la partie gauche, et celle des chasses impériales du Nouvel An reproduites dans la partie droite);

14 - I. Arzhantseva, O. Inevatkina, "Afrasiab wall-paintings revisited: new discoveries twenty-five years old (version anglaise de l'article recensé dans Abs. Ir. 28, 52);

15 A. Barbet, "Techniques d'exécution des peintures murales du palais d'Afrasiab à Samarcande » (nouvelles analyses des pigments et des tracés préparatoires, suivies de révisions parfois très importantes révélant une intervention des commanditaires, ainsi pour la diminution du nombre des Chinois par rapport aux Turcs; par ailleurs deux mains différentes sont identifiées dans l'exécution finale, un peintre de cour proprement dit, surtout attentif aux costumes, qui a peint les murs ouest et sud, et un peintre mieux doué pour les anatomies, qui a peint les murs est et nord).

\section{INDEX}

Thèmes : 1.2. Recueils d'articles : revues, colloques, ouvrages collectifs

\section{AUTEURS}

FRANTZ GRENET

CNRS - EPHE - Paris 